\section{Commentary: One size might not fit all: Planning ventricular assist device implantation in young children}

\author{
T. Konrad Rajab, MD, and \\ Minoo N. Kavarana, MD, FACS
}

Often the most complex situations in pediatric cardiothoracic surgery involve intraoperative decision making while utilizing unconventional techniques under time pressure. Thoughtful preoperative surgical planning can facilitate ventricular assist device (VAD) implantation in children.

The Berlin Heart EXCOR is the only Food and Drug Administration-approved VAD for use in small children. ${ }^{1}$ However, the associated morbidity, large driver, and lack of discharge to home capability compares poorly with the more current intrapericardial, continuous-flow VADs approved for use in adults. Therefore, adult devices are being increasingly used in children. The HeartWare HVAD is a relatively small intrapericardial, continuous-flow device that has been implanted in children with a body weight as low as $13 \mathrm{~kg}$ and body surface area as low as $0.6 \mathrm{~m}^{2}$.,3 Sometimes adjunct techniques are necessary, which may involve modification of the sewing-ring with felt bumpers or excision of the mitral valve and papillary muscles to avoid cannula obstruction. ${ }^{4}$ However, implantation of the HVAD in young children requires a personalized surgical strategy to confirm that the device will fit in both the ventricular cavity and the thoracic cavity.

A useful method to determine whether the HVAD can fit in the left ventricular (LV) cavity of a child was described

\footnotetext{
From the Section of Pediatric Cardiothoracic Surgery, Medical University of South Carolina, Charleston, SC.

Disclosures: The authors reported no conflicts of interest.

The Journal policy requires editors and reviewers to disclose conflicts of interest and to decline handling or reviewing manuscripts for which they may have a conflict of interest. The editors and reviewers of this article have no conflicts of interest.

Received for publication Nov 28, 2020; revisions received Nov 28, 2020; accepted for publication Dec 15, 2020; available ahead of print Dec 25, 2020.

Address for reprints: Minoo N. Kavarana, MD, FACS, Professor of Surgery, Section of Pediatric Cardiothoracic Surgery, Medical University of South Carolina, 10 McClennan Banks Drive, Charleston, SC 29425 (E-mail: kavarana@musc.edu). JTCVS Techniques 2021;6:142-3

2666-2507

Copyright (C) 2020 The Authors. Published by Elsevier Inc. on behalf of The American Association for Thoracic Surgery. This is an open access article under the CC BY-NCND license (http://creativecommons.org/licenses/by-nc-nd/4.0/).

https://doi.org/10.1016/j.xjtc.2020.12.006
}

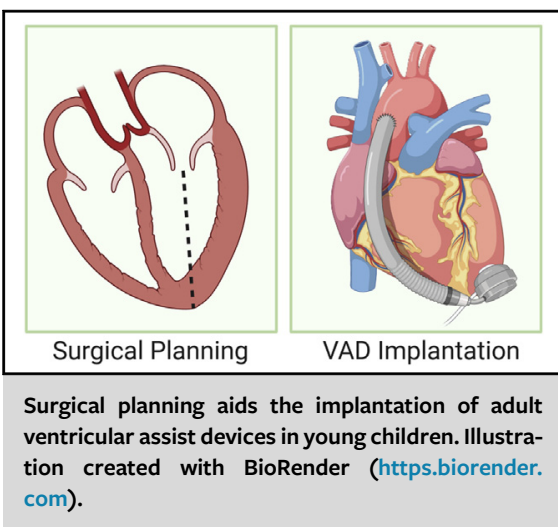

CENTRAL MESSAGE

Preoperative planning facilitates

the implantation of ventricular

assist devices in young children.

by Peng and colleagues. ${ }^{5}$ This method is based on the distance in diastole from the tip of the anterior mitral valve leaflet to the LV apex (Figure 1). We have found this method to be reliable and reproducible.

In this issue of the Journal, Davies and colleagues ${ }^{6}$ describe virtual reality-simulated implantation for fittesting the HVAD in children. This involves a computergenerated experience based on computed tomography (CT) scan reconstructions to simulate the fit of a HVAD phantom in relation to the child's heart and chest wall. For a good LV fit, the tip of the simulated HVAD inflow should lie distal to the plane of the mitral valve annulus and away from the mitral valve leaflets. Unlike echocardiography, CT scans do not resolve valvar structures well, and used in isolation this method of fit testing may be inferior to the method described by Peng and colleagues. ${ }^{5}$ In contrast, virtual reality fit-testing is well suited for testing the thoracic fit, because chest wall structures are better resolved by CT. Therefore, virtual reality fittesting allows for accurate prediction of the relationship between the HVAD and the chest wall. The authors used this information to guide the location of pump fixation to the chest wall.

These considerations indicate that a single method may not suit all patients when planning VAD implantation in children. Intraventricular fit may be assessed most reliably by the echocardiographic distance between the anterior leaflet of the mitral valve to the LV apex in diastole. In contrast, intrathoracic fit may be assessed most reliably using virtual reality-simulated implantation based on CT scan 
reconstruction and in combination provide the surgeon with the necessary information to tailor the VAD implantation technique to the specific patient.

\section{References}

1. Morales DLS, Almond CSD, Jaquiss RDB, Rosenthal DN, Naftel DC, Massicotte MP, et al. Bridging children of all sizes to cardiac transplantation: the initial multicenter North American experience with the Berlin Heart EXCOR ventricular assist device. J Heart Lung Transplant. 2011;30:1-8.

2. Miera O, Potapov EV, Redlin M, Stepanenko A, Berger F, Hetzer R, et al. First experiences with the HeartWare ventricular assist system in children. Ann Thorac Surg. 2011;91:1256-60.
3. Miera O, Kirk R, Buchholz H, Schmitt KR, VanderPluym C, Rebeyka IM, et al. A multicenter study of the HeartWare ventricular assist device in small children. $J$ Heart Lung Transplant. 2016;35:679-81.

4. Glass L, Savage A, Haddad O, Kavarana MN. Continuous-flow, implantable biventricular assist device as bridge to cardiac transplantation in a small child with restrictive cardiomyopathy. J Heart Lung Transplant. 2018;37: 173-4.

5. Peng E, Kirk R, Wrightson N, Duong P, Ferguson L, Griselli M, et al. An extended role of continuous-flow device in pediatric mechanical circulatory support. Ann Thorac Surg. 2016;102:620-7.

6. Davies RR, Hussain T, Tandon A. Using virtual reality simulated implantation for fit-testing pediatric patients for adult ventricular assist devices. J Thorac Cardiovasc Surg Tech. 2021;6:134-7. 